\title{
Real-time forecasts of flood hazard and impact: some UK experiences
}

\author{
Steven J. Cole ${ }^{1, a}$, Robert J. Moore ${ }^{1}$, Steven C. Wells ${ }^{1}$ and Paul S. Mattingley ${ }^{1}$ \\ ${ }^{1}$ Centre for Ecology \& Hydrology, Wallingford, Oxfordshire, OX10 8BB, UK
}

\begin{abstract}
Major UK floods over the last decade have motivated significant technological and scientific advances in operational flood forecasting and warning. New joint forecasting centres between the national hydrological and meteorological operating agencies have been formed that issue a daily, national Flood Guidance Statement (FGS) to the emergency response community. The FGS is based on a Flood Risk Matrix approach that is a function of potential impact severity and likelihood. It has driven an increased demand for robust, accurate and timely forecast and alert information on fluvial and surface water flooding along with impact assessments. The Grid-to-Grid (G2G) distributed hydrological model has been employed across Britain at a $1 \mathrm{~km}$ resolution to support the FGS. Novel methods for linking dynamic gridded estimates of river flow and surface runoff with more detailed offline flood risk maps have been developed to obtain real-time probabilistic forecasts of potential impacts, leading to operational trials. Examples of the national-scale G2G application are provided along with case studies of forecast flood impact from (i) an operational Surface Water Flooding (SWF) trial during the Glasgow 2014 Commonwealth Games, (ii) SWF developments under the Natural Hazards Partnership over England \& Wales, and (iii) fluvial applications in Scotland.
\end{abstract}

\section{Introduction}

Major UK floods over the last decade have motivated significant technological and scientific advances in operational flood forecasting and warning. In part this has been driven by the UK Government's Pitt Review [1] of the summer 2007 floods which has increased focus on surface water flooding and distributed, national-scale hydrological modelling. Following the Pitt Review, new joint forecasting centres between the national hydrological and meteorological operating agencies have been formed: the Flood Forecasting Centre (FFC) over England \& Wales and the Scottish Flood Forecasting Service (SFFS). Both joint centres issue a daily, national Flood Guidance Statement (FGS) to the emergency response community based on a Flood Risk Matrix approach that is a function of potential impact severity and likelihood [2,3]. To support the FGS approach there is an increased demand for robust, accurate and timely forecast and alert information on fluvial and surface water flooding along with impact assessments at local, authority area and national scales.

The Grid-to-Grid (G2G) distributed hydrological model has been employed by FFC [4] and SFFS [5] since 2010/11 to support 5-day ahead national fluvial flood forecasts using deterministic and ensemble rainfall products from the Met Office. As a first step, forecast fluvial flood severity (in terms of return period) has been used as a surrogate for impact. Recent research has explored linking the forecast fluvial flood severity to more detailed offline flood risk assessments that use an overall impact score combining human health, economic, cultural and environmental factors. This builds on a similar approach developed for surface water flooding (SWF) under the Natural Hazards Partnership (NHP) initiative, where impact assessments for detailed offline pluvial flood maps utilise national receptor datasets on population, infrastructure property and transport. Then dynamic gridded surface-runoff estimates from G2G can be equated to effective rainfall scenarios - previously used as input to inundation models when creating the pluvial flood maps - in order to select the appropriate impact assessment for each pixel and generate real-time maps of SWF impact.

Firstly a brief introduction to the G2G Model and its national application for flood forecasting is given. Then the Flood Risk Matrix approach is introduced along with three case studies of forecasting flood impact. These concern: (i) an operational SWF trial by SFFS during the Glasgow 2014 Commonwealth Games, (ii) SWF developments for FFC over England \& Wales under the NHP, and (iii) fluvial flooding over Scotland.

\section{The Grid-to-Grid (G2G) Hydrological Model}

The Grid-to-Grid Model, or G2G, is a physicalconceptual distributed hydrological model developed by the Centre for Ecology \& Hydrology [7-9]. A major driver in the development of $\mathrm{G} 2 \mathrm{G}$ was to simulate surface runoff and river flow over ungauged areas. Its formulation and configuration utilises spatial datasets on landscape properties related to terrain, land-cover, soil

\footnotetext{
${ }^{\mathrm{a} C}$ Corresponding author: scole@ceh.ac.uk
} 


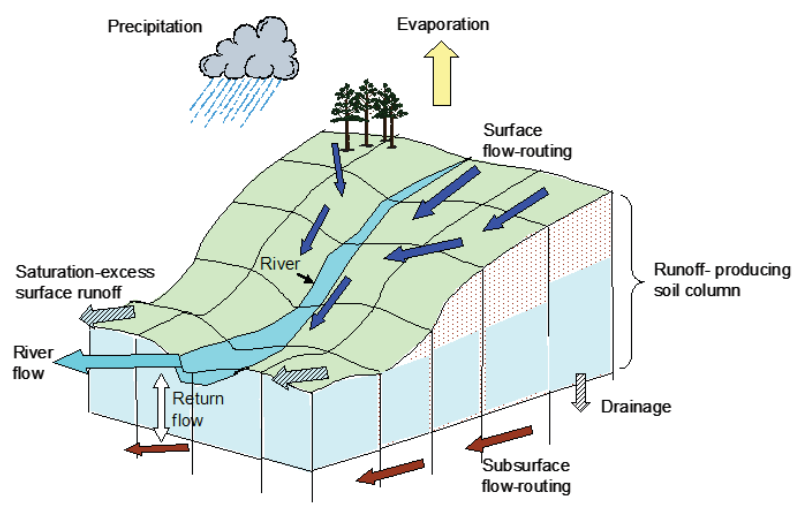

Figure 1. Schematic of the Grid-to-Grid Model.

and geology. When used with gridded time-series of rainfall, G2G is able to shape a rainfall pattern into a river flow response over the model domain. A model schematic is shown in Figure 1.

G2G national deterministic and ensemble forecasts are produced routinely several times a day, every day, by the FFC [4] and SFFS [5] as evidence support to the daily Flood Guidance Statements. G2G is currently configured to operate at a $1 \mathrm{~km}$ resolution across Britain and uses a 15 minute output time-step. This aligns to the frequency of river flow observations which can be assimilated within $\mathrm{G} 2 \mathrm{G}$ to improve forecasts through a variety of techniques: (i) direct flow insertion of observed flows to improve forecast performance at locations downstream of a river gauging station, (ii) a simple empirical stateupdating scheme which adjusts model states to achieve better alignment of modelled and observed flows, and (iii) model errors can be used to forecast future errors using an Auto-Regressive Moving Average (ARMA) error-predictor and in turn produce an internally updated flow forecast for each gauged river location.

As G2G gridded outputs of river flow or surface runoff are generated routinely in ensemble form, they offer the potential to be interfaced with different types of receptor impact datasets to generate real-time flood impact assessments at national- and regional-scale.

\section{The Flood Risk Matrix approach}

The FFC and SFFS both issue a national Flood Guidance Statement (FGS) on a daily basis and more frequently during an emerging flooding situation [2, 3]. Principal recipients of the FGS are the Category 1 and 2 emergency responders identified in the Civil Contingencies Act 2004 [6]. The FGS is based on a Flood Risk Matrix approach that combines potential impact severity and likelihood of occurrence as depicted in Figure 2.

Several different types of impact are considered including people, property, transport and key infrastructure. These are also assessed at increasing severity levels of: Minimal, Minor, Significant and Severe. For example, localised flooding affecting individual properties is considered a Minor impact whilst widespread flooding affecting significant numbers of properties and whole communities is considered Severe. Full details are provided in the FFC and SFFS guides to the FGS [2, 3]. The "likelihood" classification of the Flood Risk Matrix (Figure 2) is defined using the following probability of occurrence bands: very low $<20 \%$, low $20-40 \%$, medium $40-60 \%$, high $60 \%$ or greater.

\section{Operational SWF alert trial during the Glasgow 2014 Commonwealth Games}

The Scottish Environment Protection Agency (SEPA) has a commitment to develop appropriate forecasting and warning capabilities for Surface Water Flooding (SWF) in Scotland. In recent years there have been several notable floods resulting from intense rainfall in urban areas exceeding the capacity of local drainage systems.

Glasgow has a history of surface water flooding with five notable events in the 12 year period 2002 to 2013 . A flood in July/August 2002 was particularly severe with many houses and transport infrastructure affected. From 23 July to 3 August 2014, Glasgow was the host venue for the Commonwealth Games and this provided a unique opportunity and focus for developing and trialling a new Daily Surface Water Flood Forecast (DSWFF) service over a 10 by $10 \mathrm{~km}$ area of Glasgow.

A collaborative project, funded by the Scottish Government, was commissioned through the Scottish Centre of Expertise for Waters (CREW, www.crew.ac.uk) with SEPA as the principal stakeholder. The research project brought together expertise from the James Hutton Institute, the Met Office

Flood Risk Matrix

(river, tidal/coastal \& surface water flooding)

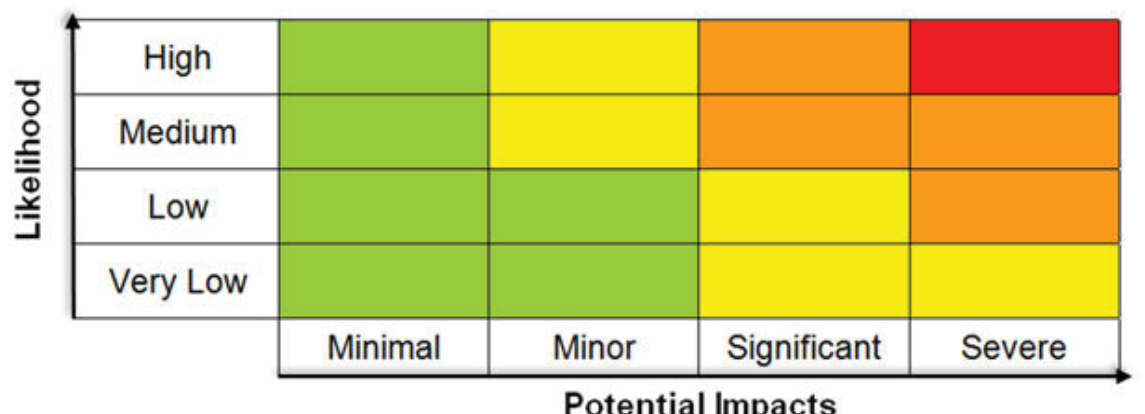

Potential Impacts
Overall Flood Risk

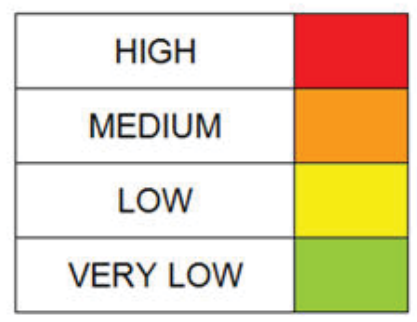

Figure 2. The Flood Risk Matrix used in generating Flood Guidance Statements [2, 3]. 
and Centre for Ecology \& Hydrology. Operational implementation of the trial was managed by SEPA with additional system configuration support provided by Deltares. Full details are given in [10] whilst a summary follows.

\subsection{Review of approaches for forecasting intense rainfall and surface water flooding}

A first phase reviewed approaches for forecasting intense rainfall and surface water flooding. The review highlighted that due to convective storms being a main source of rainfall for surface water flooding, highresolution Numerical Weather Prediction (NWP) models that capture the dynamics of convection explicitly should be used. Moreover, ensemble rainfall forecasts are required to capture the remaining spatio-temporal uncertainty in the rainfall forecast.

Within the operational trial, the Met Office Global and Regional Ensemble Prediction System (MOGREPS) [11] was used to produce short-range (36 hours) rainfall forecasts over the UK at $2.2 \mathrm{~km}$ resolution with 12 members. These forecasts are subsequently downscaled to $2 \mathrm{~km}$ and blended with extrapolated radar rainfalls within the Short-Term Ensemble Prediction System (STEPS) [12-14] to produce a 24-member ensemble of 15 minute rainfall accumulations. These blended short-range ensemble forecasts were available four times a day. As updates in between, four nowcast ensemble forecasts were used in the form of a STEPS radar-extrapolation ensemble nowcast out to 7 hours with 24-members.

Although detailed 2-D hydraulic surface water flood inundation models exist and are widely used in design and research activities, none were found to be ready for real-time use without substantial additional development. Potential issues included how to create appropriate realtime "effective rainfall" inputs as the methods used for design storm profiles may not include an explicit spacetime representation of runoff production and water loss accounting. In addition, the computing requirements notably for fully coupled sewer and 2-D hydraulic models - were seen as prohibitive in the particular application context where ensemble outputs have to be available within an acceptable time-frame to be of operational use.

The G2G distributed hydrological model was selected for the SWF trial as it was already running within the SFFS/SEPA national operational system (FEWS (Flood Early Warning System) Scotland [15]) and could output surface runoff forecasts to give an indication of the SWF hazard footprint. An important strength of the G2G continuous modelling approach, over alerts based on rainfall thresholds only, is that dependence on surface cover, soil properties and antecedent wetness conditions are implicitly included in the $\mathrm{G} 2 \mathrm{G}$ formulation. The $\mathrm{G} 2 \mathrm{G}$ is also relatively quick to run with national ensembles already routinely produced within operational time-frame requirements. Furthermore, complementary work under the NHP had illustrated the potential for linking gridded hydrological model hazard footprints with datasets on impact to provide real-time impact forecasts. For SWF this could be achieved by equating the real-time G2G surface runoff estimates with the "effective rainfall" inputs used to generate off-line design flood maps and impacts.

\subsection{Methodology for impact assessments}

Regional Pluvial Flood Hazard (RPFH) design maps and associated static impact assessments have been developed by SEPA across Scotland [16]. For the Glasgow pilot area, the maps used were based on the JFlow + model using a 2m DEM [17]. Maps were produced for 14 scenarios using 5 rainfall return periods $(10,30,50,100$ and 200 years), 2 climate change uplift scenarios (30 year $+20 \%, 200$ year $+20 \%)$ and 2 different durations ( 1 and 3 hours). The "effective rainfall" used as input to the inundation modelling allows for a percentage runoff of $55 \%$ in rural areas and $70 \%$ in urban areas. Losses to urban drainage systems were assumed to be the 5 -year return period rainfall.

Static impact assessments were made for each of the flood maps for each rainfall scenario (for the 3 hour duration only) against the following six different receptors.

- Population (number of properties affected per $1 \mathrm{~km}$ pixel: e.g. 1-50, 51-100)

- Community Services (point locations)

- Utilities (point locations)

- Commercial Properties (point locations)

- Railway (lines of affected railway)

- Roads (lines of affected roads)

In order to use the FGS approach (Section 3), $1 \mathrm{~km}$ grid-cell impact severity definitions needed to be derived for each of the six receptors. The receptors were also grouped into people and property (population, community services, utilities, commercial properties) and transport (railway and road). Transport was considered as a separate category, since impacts in any one grid-cell are likely to cause significant disruption across a wider area.

\begin{tabular}{|c|c|c|}
\hline $\begin{array}{c}\text { Impact } \\
\text { Category }\end{array}$ & People and Property & Transport \\
\hline Minor & $\begin{array}{l}1-100 \text { residential properties } \\
1-2 \text { community services } \\
1-2 \text { utilities } \\
1-20 \text { commercial properties }\end{array}$ & \\
\hline Significant & $\begin{array}{l}\text { 1-100 residential properties } \\
>2 \text { community services } \\
>2 \text { utilities } \\
>20 \text { commercial properties }\end{array}$ & $\begin{array}{l}>5 \mathrm{~m} \text { road } \\
>5 \mathrm{~m} \text { railway }\end{array}$ \\
\hline Severe & $>100$ residential properties & \\
\hline
\end{tabular}

For each of the effective rainfall scenarios, a $1 \mathrm{~km}$ "impact classification map" was derived for each receptor using the impact definitions in Table 1. Then, for individual or grouped receptors, a $1 \mathrm{~km}$ "minimum effective rainfall map" was calculated for each impact category: that is, the lowest effective rainfall threshold that gives that level of impact. 


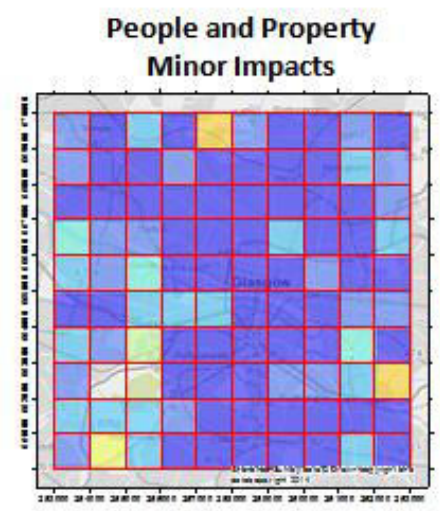

Rail Significant Impacts

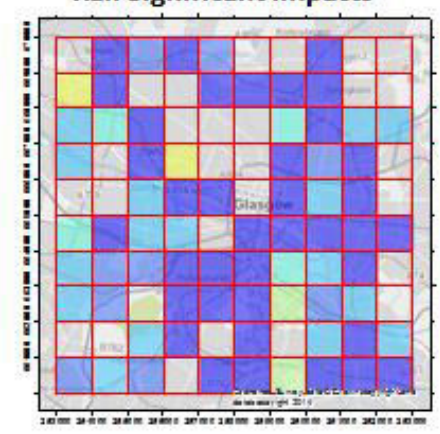

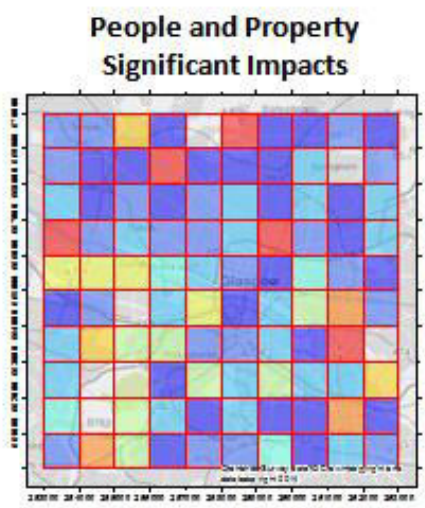

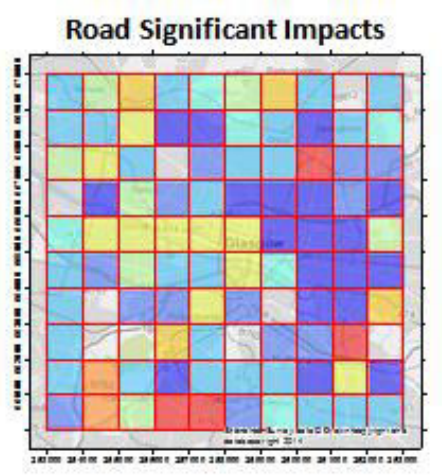

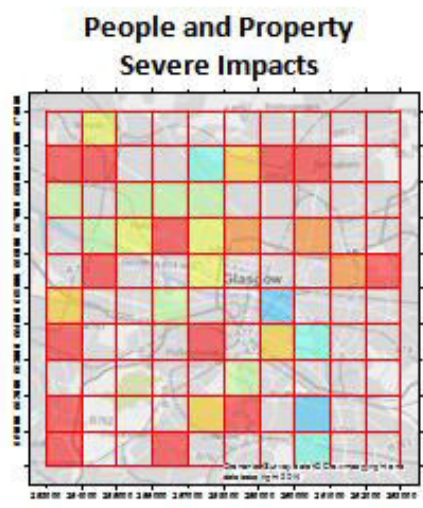
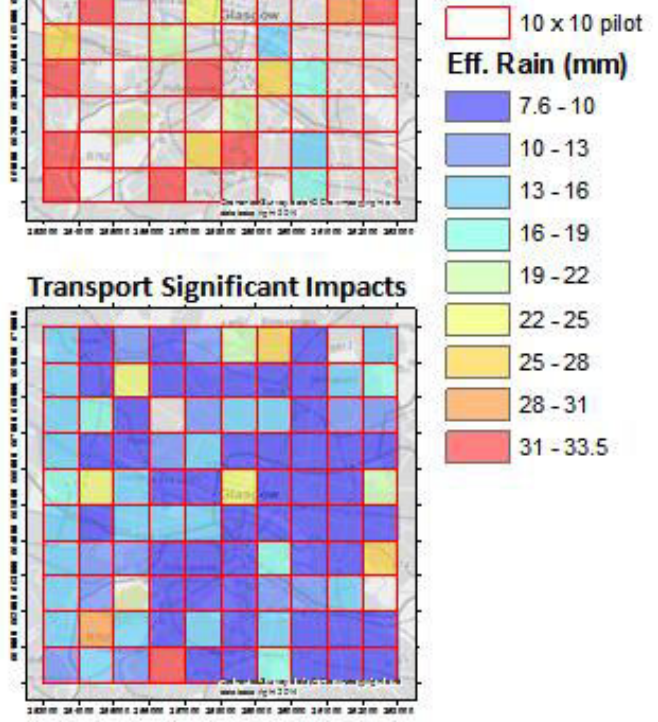

\section{Eff. Rain (mm)}

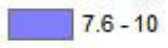

$10-13$

$13-16$

$16-19$

$19-22$

$22-25$

$25-28$

$28-31$

$31-33.5$

Figure 3. The six minimum effective rainfall threshold grids used in the final "impact library".

Whole forecast

$T+3 \mathrm{~h}-\mathrm{T}+27 \mathrm{~h}$

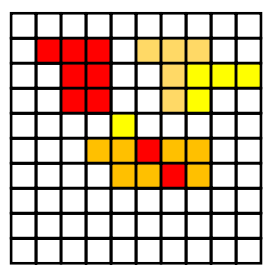

Likelihood

$\square$ high (>60\%)

$\square$ medium (40-60\%)

$\square \operatorname{low}(20-40 \%)$

$\square$ very low $(<20 \%)$

Figure 4. Illustration of how gridded maps of threshold exceedance probabilities can be presented for part- and whole-periods over the forecast horizon. A significant Flood Risk Matrix impact threshold is assumed.

An offline "impact library" containing the following six minimum effective rainfall threshold grids is presented in Figure 3: People and Property $\times 3$ (minor, significant, severe), Significant $\times 3$ (railways, roads and combined railways and roads (transport)). This "impact library" can then be used with the real-time G2G surface runoff grids to generate real-time impact forecasts as detailed in the next Section.

\subsection{Display of probabilistic impact outputs}

Novel methods for presenting the wealth of ensemble forecast model and impact output were required to support operational decision-making in time-pressured situations. The operational hydrometeorologist requires enough information and transparency to understand how the automated surface water flooding forecast and impact products are constructed without being overwhelmed by information. A key concept is to summarise ensemble outputs over a forecast time-horizon and ensuring consistency with the "likelihood" classifications and colours of the Flood Risk Matrix (Figure 2, Section 3).
A generic illustration of the approach is presented in Figure 4 for a forecast starting at time $T$. The process is, for each ensemble member, calculate a 15 minute sequence of 3 hour accumulations (surface runoff or rainfall) and note, for each pixel, if the accumulation exceeds the threshold under consideration. When completed for all ensemble members, a grid of threshold exceedance probabilities can be calculated and displayed. This can be applied to the whole forecast as a useful overview (right hand map) and also to time-windows within the forecast to understand how the risk evolves in time. The illustration shows how the exceedance probabilities over the whole forecast must be equal to or greater than the exceedance probabilities for any of the sub-parts of the forecast. A "significant" Flood Risk Matrix impact threshold (Figure 2) is illustrated in Figure 4 and the likelihoods coloured accordingly to represent the risk.

A sequence of such maps could be created for each of the six threshold grids within the "impact library". A similar approach could also be applied to either the rainfall or surface runoff ensembles relative to a static threshold (e.g. $20 \mathrm{~mm}$ in $3 \mathrm{~h}$ for rainfall, 13.5 or $16 \mathrm{~mm}$ in 
$3 \mathrm{~h}$ for surface runoff). Furthermore, Overall risk maps can be calculated for the combined People and Property and Transport impact categories where the highest risk (across all relevant impact thresholds/receptors) is stored.

Through discussion with users, it was decided that the overview page to a particular forecast would contain maps for the whole forecast period for each of the six "impact library" layers, plus the overall risk, plus the rainfall and surface runoff exceedance maps. This would give a high-level overview that could be quickly assessed by operational users who could then drill down to find out extra information like the sub-forecast time-window displays if needed. The Overall risk maps were also used for onward communication within the Daily Surface Water Flood Forecast. An example from the operational system displaying the Overall risk together with the rainfall and surface runoff maps is shown in Figure 5.

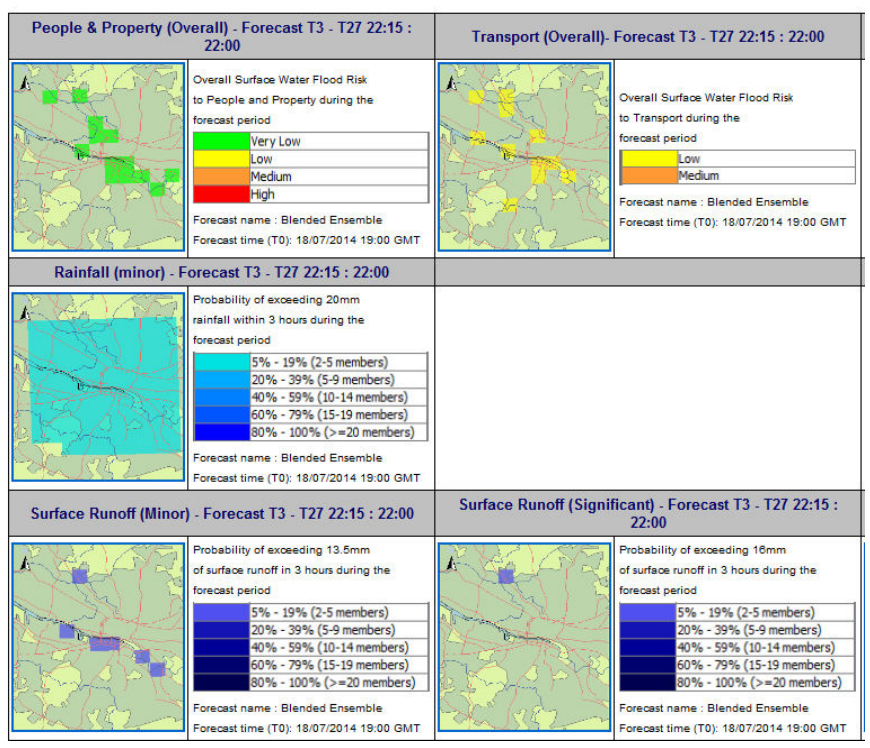

Figure 5. FEWS Glasgow 24 hour Summary using the blended ensemble forecast from 19:00 18 July 2014.

\subsection{Operational trial and next steps}

A separate forecast system, FEWS-Glasgow, was setup to implement the operational SWF trial. This produced web reports triggered by the receipt of new rainfall ensemble data and took only 3 minutes to run over the case study area. Operational users and the project team could view the displays remotely. The system operated throughout the summer of 2014 with the Glasgow Daily Surface Water Flood Forecast (DSWFF) issued daily at 17:00 to responders during the period of the Commonwealth Games. This time was chosen to align with the formal briefing schedule of the Games Multi Agency Control Centre.

Although the weather during the Games was generally fine, feedback from responders indicated that there were instances where the DSWFF outputs provided invaluable additional information and allowed more informed decisions to be made. This broadly fell into two categories. Firstly, the DSWFF could add advice that, although heavy rainfall was forecast in the wider West Central Scotland region, flooding impacts in Glasgow itself were unlikely. For example on the 18/19 July there was a regional low risk (yellow) for SWF from the national FGS but a more targeted, lower risk forecast could be provided for Glasgow (see Figure 5). Secondly, as was the case on the last weekend of the Games (2-3 August), the tool could provide additional targeted information on the timing, likely impacts and possibility of flooding in Glasgow. More details are provided in [10].

Overall, the operational SWF trial was deemed a success and represents a step-change in operational capability for the Scottish Flood Forecasting Service. The trial system could easily operate within the existing SEPA computing infrastructure for the localised case study area. The use of nationally available hydrological models and impact datasets facilitates the application to other regions. There are some important points to consider going forward. The operation during the Glasgow 2014 Commonwealth Games benefited from close stakeholder engagement throughout the project and subsequent trial. However, providing the service was resource intensive and efficiencies when/if rolled out wider need to be sought. This includes considering how to automatically generate a city-wide or area summary (i.e. one overall risk forecast), appropriate engagement with relevant stakeholders and methods for communication.

\section{Natural Hazards Partnership SWF Hazard Impact Model}

Prior, and in parallel, to the Glasgow SWF trial, the Natural Hazards Partnership (NHP) had been developing a Surface Water Flooding Hazard Impact Model (HIM). The NHP aims to deliver coordinated assessments, research and advice on natural hazards for governments and resilience communities across the UK. Within the NHP SWF HIM, the Centre for Ecology \& Hydrology $(\mathrm{CEH})$ are working with the Health and Safety Laboratory (HSL), Met Office and Environment Agency (EA) to develop a real-time end-to-end trial SWF HIM system for the whole of England and Wales with the primary aim of improving the FGS service delivered by the FFC.

\subsection{Methodology, similarities and differences with the Glasgow trial}

Initial developments of the NHP SWF HIM and further background is provided in [18]. The methodology has since developed further and has many parallels with the Glasgow prototype. For example, G2G surface runoffs are being used to estimate the SWF hazard footprint in real-time and linked to impacts through detailed offline flood maps (based on JFlow + ) and an associated "impact library". The Flood Risk Matrix approach is also being used in both trials.

However, there are some important differences. The most important is that the NHP SWF HIM aims to cover the whole of England \& Wales, not just a focussed 10 by $10 \mathrm{~km}$ area as in the Glasgow study. To support the national coverage, regional impact summaries aligned to 
the county/unitary authority areas used in the FGS are required.

Some of the other differences are outlined in what follows. The detailed flood maps for England and Wales (called the updated Flood Map for Surface Water, uFMfSW [19]) were produced using the same JFlow + modelling but the "effective rainfall" calculations and rainfall scenarios involved are different. Nine different design storms are used to generate the baseline national uFMfSW maps for the nine combinations of three durations (1, 3 and 6 hours) and three rainfall return periods $(30,100$ and 1,000 years). The effective rainfall calculations of the uFMfSW use the Revitalised Flood Hydrograph (ReFH) model approach for rural squares and a $70 \%$ runoff coefficient with a $50 \%$ "summer" design storm profile [20] for urban locations. Losses due to urban drainage capacity are limited to a specified rate, usually $12 \mathrm{~mm} \mathrm{~h}^{-1}$. A consequence of this formulation is that total urban effective rainfall can decrease with duration for a given return period and also be less than rural pixels [19].

The readily available uFMfSW outputs are one flood map per return period, referred to as the "Maximum Outputs". The flood outline for each return period is based on the maximum Hazard Rating (calculated as a function of depth and velocity [19]) from the three durations exceeding 0.575 . Within the flood outline, the "Maximum Outputs" grids contain the worst case for each output (depth, velocity, hazard) over all durations and the Critical Storm Duration (CSD) of the maximum is stored for each pixel. However, the CSD is not a standard output readily available from the uFMfSW so a 3 hour duration has been assumed.

The "Maximum Outputs" $2 \mathrm{~m}$ grids for depth, duration and velocity are used by HSL together with national receptor databases (e.g. National Population Database (NPD) [22], National Receptors Database (NRD) [23]) to derive impact [21]. Five different impact criteria are considered.

- Danger to life

- Danger to buildings

- Disruption of key sites and information

- Disruption of transport

- Disruption of communities
For each of the five criteria, receptor rules are derived to decide when each impact has reached Minimal (1), Minor (2), Significant (3) or Severe (4) impacts at a $1 \mathrm{~km}$ level. These calculations are generally more involved and include more categories than those used in the Glasgow trial (Table 2).

As there are only three rainfall return period scenarios used in the current NHP SWF HIM approach (although the benefit of using all 9 is under investigation), the "impact library" consists of grids of "impact severity" for each impact criteria and return period rather than the "minimal effective rainfall" grids used in the Glasgow trial (Section 4.2).

A similar process to Section 4.3 is used to interface the G2G surface runoff outputs with the "impact library". In the case of NHP, the maximum 3 hour surface runoff accumulation for each pixel over a given forecastwindow is compared to the three uFMfSW effective rainfall grids (one for each return period) and the highest return period exceeded is noted for each pixel. This is then used to look up the appropriate impact library layer on a pixel by pixel basis. The process of generating the G2G SWF hazard footprint and its classification by uFMfSW effective rainfall scenarios is illustrated in Figure 6. This highlights the spatial heterogeneity in the G2G response (due to the supporting landscape spatial datasets used by the model) and the heterogeneity in the uFMfSW rainfall thresholds.

\subsection{Ensemble Outputs and Regional Summaries}

Probabilities of exceeding each of the four impact categories can be calculated on a pixel by pixel basis and coloured according to the Flood Risk Matrix risk categories (Figure 2), as in the Glasgow study. However, it is important to note that any regional summaries beyond the $1 \mathrm{~km}$ resolution (e.g. county or unitary authority) need to be calculated on an ensemble member basis before assessing the likelihood in order to maintain the spatial integrity of the forecasts. Within the NHP SWF HIM, HSL have developed a simple regional summary methodology [21] based on percentage of areal coverage for assigning the impact category at a regional

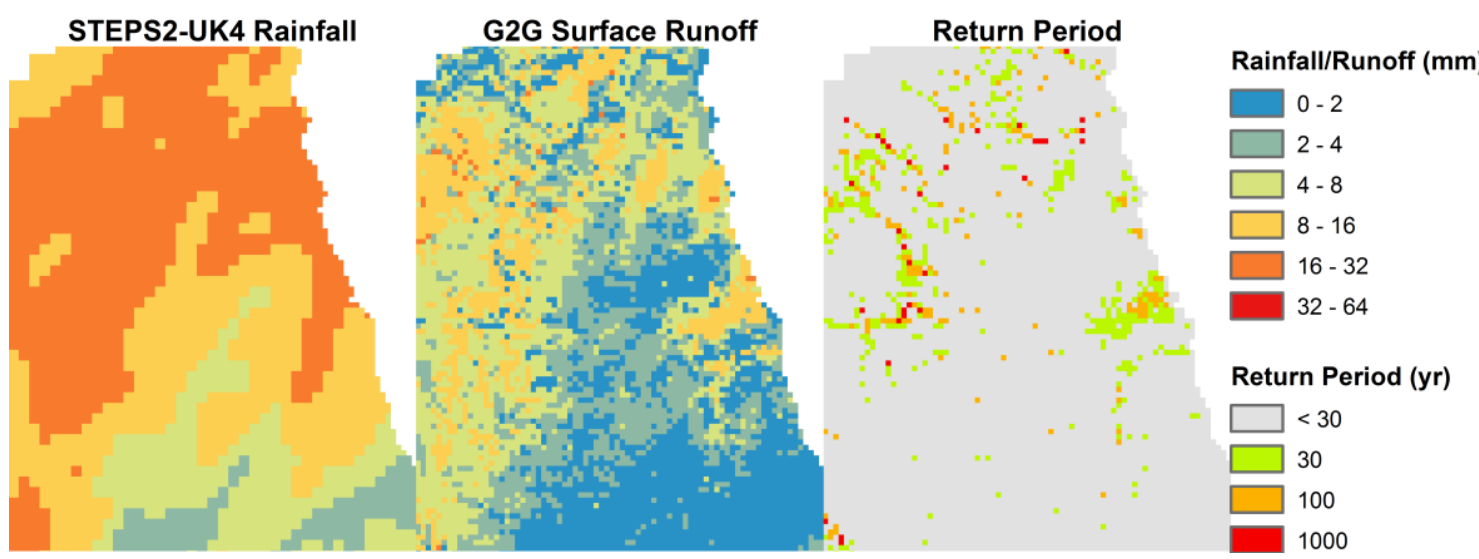

Figure 6. Illustration of the G2G SWF Hazard Footprint output generation using a single ensemble member.

Left plot: maximum 3-hr rainfall total over the entire forecast. Middle plot: maximum 3-hr G2G surface runoff total over the entire forecast (note same scale as rainfall). Right plot: classification of maximum runoff by uFMfSW effective rainfall thresholds. 
level. For example, if $1 \%$ of the region is classed as Severe then the region is Severe for that ensemble member.

\subsection{Case study example}

Through the NHP activity, several offline case studies have been used to develop the NHP SWF HIM. A particularly extreme flooding event occurred on 28 June 2012 with notable flooding from surface water and small rivers. The most significant impacts were recorded in north-east England and Tyneside, with the closure of the A1 main road along with many minor roads and the flooding of Newcastle Rail Station. Flooding resulted from convective rainfall with two particularly vigorous lines of thunderstorms crossing from Wales and the Midlands towards north-east England. Hourly rainfall totals of $20-30 \mathrm{~mm}$ were common with up to $40-50 \mathrm{~mm}$ in some locations.

For this cases study, 12-member ensemble rainfall forecasts out to $\mathrm{T}+24$ hours were available, updated four times a day. A $4 \mathrm{~km}$ configuration of the Met Office Unified Model (MetUM UK4) was used as a deterministic NWP input to the STEPS blending and downscaling methodology and was a precursor to the MOGREPS-UK based ensembles described in Section 4.1.

A regional impact summary from the SWF HIM is presented in Table 2 for four counties in north-east England. Each row relates to a different forecast and each column indicates how many ensemble members exceed that impact category for the region. They are colourcoded according to the risk level as used in the Flood Risk Matrix (Figure 2). The bottom row presents a postevent estimate of what the FFC hydrometeorologists assessed the impact to be and the forecast likelihood they would have expected from the meteorological situation.
The regional impact summary presented in Table 2 shows how the forecasts evolve over time and demonstrate reasonable alignment with the two risk estimates provided by the FFC, noting that the Tyne and Wear forecasts were slightly less severe than experienced. Nevertheless, the results indicate the potential benefit that such a Hazard Impact Model approach could bring. More detailed analysis of the impact calculations is provided in [21] for this case study. Ongoing work within NHP is considering the sensitivity to the rules used to calculate the $1 \mathrm{~km}$ impact and testing the approach using a wider set of over 10 case studies.

To complement the detailed analysis of the impact calculations provided in [21], further insight into the hydrometeorological modelling chain is provided here. Figure 7 shows the summary of rainfall (left side) and surface runoff (right side) ensembles for the

\begin{tabular}{|c|c|c|c|c|c|c|c|c|c|c|c|c|c|c|c|c|}
\hline \multirow[t]{2}{*}{$\begin{array}{l}\text { Forecast } \\
\text { origin }\end{array}$} & \multicolumn{4}{|c|}{ Darlington } & \multicolumn{4}{|c|}{ Durham } & \multicolumn{4}{|c|}{$\begin{array}{c}\text { Northumber } \\
\text {-land }\end{array}$} & \multicolumn{4}{|c|}{$\begin{array}{c}\text { Tyne \& } \\
\text { Wear }\end{array}$} \\
\hline & 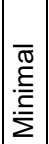 & 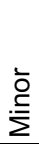 & 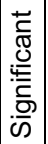 & 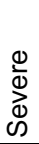 & $\begin{array}{l}\overline{\widetilde{J}} \\
\stackrel{\underline{E}}{\underline{E}} \\
\stackrel{\Sigma}{\Sigma}\end{array}$ & 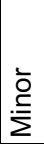 & 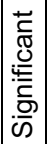 & ঐ) & 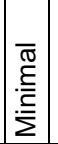 & 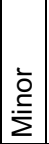 & 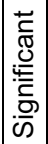 & 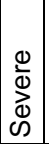 & 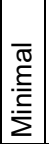 & $\stackrel{\grave{O}}{\stackrel{一}{\Sigma}}$ & 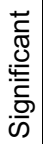 & 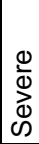 \\
\hline 27 June $07: 15$ & 12 & 0 & 0 & 0 & 12 & 0 & 0 & 0 & 12 & 0 & 0 & 0 & 12 & 0 & 0 & 0 \\
\hline 27 June $12: 15$ & 12 & 0 & 0 & 0 & 12 & 0 & 0 & 0 & 12 & 0 & 0 & 0 & 12 & 0 & 0 & 0 \\
\hline 27 June 19:15 & 12 & 6 & 5 & 0 & 12 & 8 & 5 & 0 & 12 & 10 & 3 & 0 & 12 & 5 & 3 & 0 \\
\hline 28 June 00:15 & 12 & 0 & 0 & 0 & 12 & 3 & 3 & 0 & 12 & 12 & 10 & 1 & 12 & 7 & 6 & 1 \\
\hline 28 June $07: 15$ & 12 & 4 & 2 & 0 & 12 & 8 & 4 & 0 & 12 & 10 & 7 & 0 & 12 & 8 & 8 & 1 \\
\hline 28 June $12: 15$ & 12 & 0 & 0 & 0 & 12 & 0 & 0 & 0 & 12 & 6 & 1 & 0 & 12 & 2 & 1 & 0 \\
\hline 28 June 19:15 & 12 & 0 & 0 & 0 & 12 & 0 & 0 & 0 & 12 & 0 & 0 & 0 & 12 & 0 & 0 & 0 \\
\hline $\begin{array}{l}\text { Risk estimate } \\
\text { (from FFC) }\end{array}$ & & & & & & & & & \multicolumn{4}{|c|}{$\begin{array}{l}\text { Impact: Sig } \\
\text { Likelihood: M }\end{array}$} & \multicolumn{4}{|c|}{$\begin{array}{l}\text { Impact: Sev } \\
\text { Likelihood: M }\end{array}$} \\
\hline
\end{tabular}

Table 2. NHP SWF HIM regional impact summary output for 28 June 2012 case study. The final row provides FFC's postevent judgement of impact and risk.
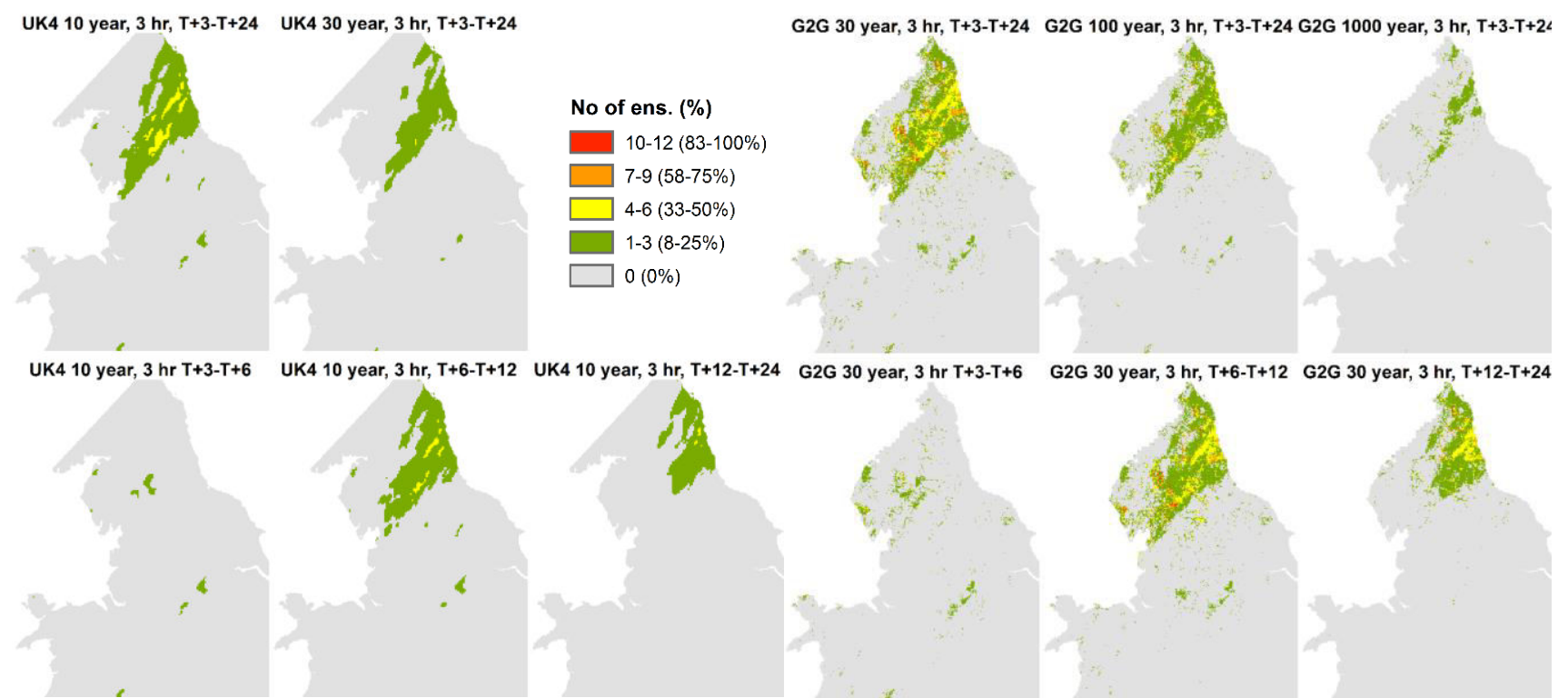

Figure 7. Summary of STEPS-2 (UK4) \& G2G Surface Runoff ensembles for the 07:15 28 June 2012 forecast. Maps show number of ensembles for which the maximum $3-\mathrm{hr}$ rainfall or surface runoff total exceeds the indicated rainfall or uFMfSW effective rainfall threshold at some point during the indicated forecast window. Left half are for rainfall, right half are for surface runoff. 
07:15 28 June forecast. Row 1 (left side) summarises the rainfall over the entire forecast window $(\mathrm{T}+3$ to $\mathrm{T}+24)$ for the two different 3-hr duration rainfall thresholds: 10yr $(30 \mathrm{~mm})$ and $30-\mathrm{yr}(40 \mathrm{~mm})$ return periods. Row 2 (left side) gives some appreciation of the temporal characteristics of the forecast by using three forecast windows $(\mathrm{T}+3$ to $\mathrm{T}+6, \mathrm{~T}+6$ to $\mathrm{T}+12$ and $\mathrm{T}+12$ to $\mathrm{T}+24)$ and the lowest return period threshold (10 years). Row 1 (right side) summarises the surface runoff over the entire forecast window $(\mathrm{T}+3$ to $\mathrm{T}+24)$ for the three different 3 hr duration uFMfSW thresholds (30-, 100- and 1000-yr return periods). Row 2 (right side) uses three forecast windows $(\mathrm{T}+3$ to $\mathrm{T}+6, \mathrm{~T}+6$ to $\mathrm{T}+12$ and $\mathrm{T}+12$ to $\mathrm{T}+24)$ and the lowest return period uFMfSW threshold (30 years).

Figure 7 highlights the national view that the G2G SWF Hazard Footprint has and also some of the spatiotemporal characteristics of this forecast. In particular, it indicates the 6 to 12 and 12 to 24 hour windows are the main contributors to the rainfall and surface runoff outputs for the 07:15 28 June forecast. This shows the additional benefits the SWF HIM approach can give in understanding the temporal aspects of the forecast.

\section{Real-time assessment of fluvial impacts over Scotland}

National gridded river flow forecasts from G2G (measured in cumecs, $\mathrm{m}^{3} \mathrm{~s}^{-1}$ ) are useful in understanding the spatio-temporal evolution of the hydrological forecast. To aid interpretation of the potential flood hazard and impact, there is a desire to provide additional context to the outputs. A first step has been to estimate the severity of the modelled flows by converting them to return period estimates so that potential flood "hotspots" can be identified. Much like in the previous discussions for SWF, this can also be undertaken in a probabilistic way using ensembles to obtain hotspots of flood risk. FFC and SFFS both use gridded outputs that show how many $\mathrm{G} 2 \mathrm{G}$ forecasts exceed a certain return period threshold over a given time window. For example, grids showing how many ensembles exceed the 10-year return period over the next 24-hours provide a very concise summary over time and ensemble members.

Within Scotland, there has been some prototype work to link the $\mathrm{G} 2 \mathrm{G}$ forecasts of flow severity (return period) with detailed offline assessments of fluvial flood risk. SEPA's National Flood Risk Assessment (NFRA) methodology [24] has produced a $1 \mathrm{~km}$ grid of combined "impact scores" taking into account human health, economic, cultural and environmental factors. For fluvial flood hazard, these are based on a 1 in $200 \mathrm{yr}$ flood extent. High scoring areas in the NFRA have been used to identify Potentially Vulnerable Areas (PVAs).

To progress the prototype fluvial impact forecasting work, the NRFA $1 \mathrm{~km}$ impact scores have been used to define Flood Risk Matrix "impact categories" for the PVAs according to area of coverage as listed in Table 3.

In the case of the NRFA impact dataset, there is only one return period flood map used. However, the

\begin{tabular}{cccc}
\hline $\begin{array}{c}\text { NRFA } \\
\text { Category }\end{array}$ & $\begin{array}{c}\text { NRFA 1km } \\
\text { score }\end{array}$ & $\begin{array}{c}\text { Impact } \\
\text { Category }\end{array}$ & $\begin{array}{c}\text { Area } \\
\text { threshold }\end{array}$ \\
\hline $\begin{array}{c}\text { High \& } \\
\text { V High }\end{array}$ & $>250$ & Severe & $>1 \%$ \\
\hline Medium & $125-250$ & Significant & $>2 \%$ \\
\hline Low & $50-125$ & Minor & $>4 \%$ \\
\hline V Low & $<50$ & Minimal & Default \\
\hline Table 3. Impact category classification for PVAs based on \\
NFRA.
\end{tabular}

methodology that follows could be extended to consider multiple flood maps. For the prototype, the ensemble G2G river flow forecasts are compared against the 200year return period flow grids and the exceedance probability is calculated for each pixel. In order to assign an exceedance probability to the PVA of interest, the exceedance probabilities are ranked and the 95 percentile used as the "likelihood". The likelihood and PVA assessment of impact category (Table 3 ) are then used to give the overall flood risk rating as in the Flood Risk Matrix. Note that Very Low likelihoods are taken to be 520\%: this avoids PVAs with a Significant or Severe impact category always being flagged as yellow (low flood risk) even if the likelihood is $\sim 0 \%$ (i.e. no ensemble members crosses the threshold).

\subsection{Case study}

On 20 September 2012 heavy rain affected northern England and southern Scotland. Several flooding impacts were reported across Ayr, Prestwick and Kilmarnock areas. The most high-profile was the closure of Prestwick Airport following $72 \mathrm{~mm}$ of rainfall in a 24 hour period and flooding of a small river. A sequence of fluvial flood impact forecasts in the run up to the event are presented in Figure 8. These use a 12-member ensemble rainfall forecast (as described in Section 5.3) to generate the ensemble $\mathrm{G} 2 \mathrm{G}$ river flow forecasts and impacts.

The fluvial flood impact maps show, in the top row, the static PVA impact category based on the NRFA data and Table 3. The likelihood is presented in the second row and finally the fluvial flood risk presented in the bottom row. Using only flood severity (middle row) provides useful information on where floods might occur but the potential benefit of including an impact assessment to derive risk (bottom) is clearly evident. In particular, the PVA containing Prestwick Airport actually attains a red risk rating of High (High likelihood of Severe impacts) during the last forecast (in southwest part of map).

There are many elements of this prototype approach that could be refined or developed further. For example, applying NRFA analysis to more return period flood maps or refining the presentation methods to include pixel based information. However, the case study serves to highlight how simple methods to combine existing real-time gridded river flow forecasts with existing impact information could provide significant added value for real-time fluvial flood risk forecasting. 

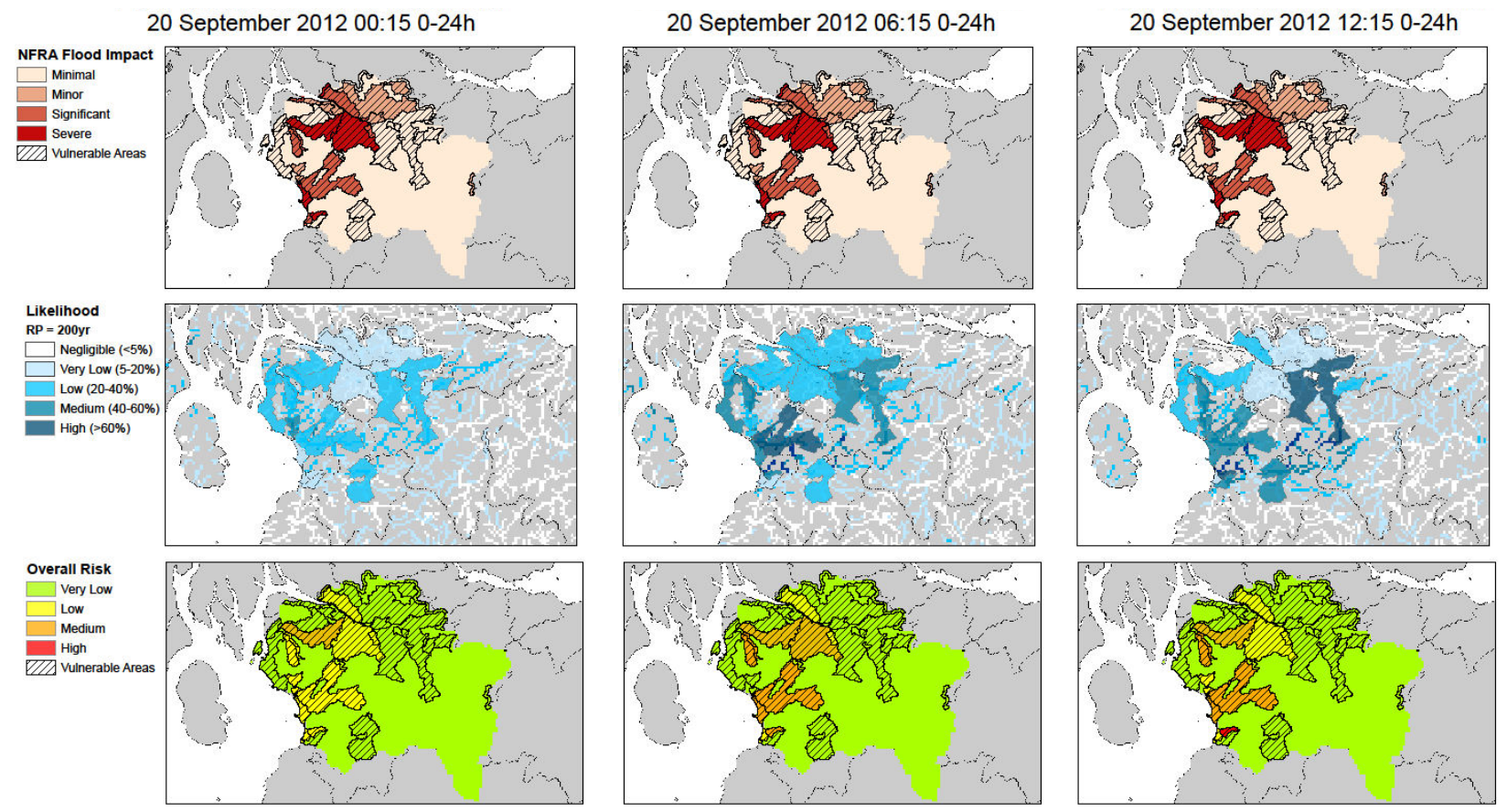

Figure 8. Fluvial flood risk forecast maps for a sequence of three forecasts during 20 September 2012. Top row: PVA impact severity based on 1 in $200 \mathrm{yr}$ NRFA data. Middle row: likelihood of each PVA exceeding a 1 in $200 \mathrm{yr}$ flood. Bottom row: forecast flood risk for PVAs.

\section{Summary and Conclusions}

There is increasing demand from stakeholders and emergency responders for robust, accurate and timely forecast and alert information on fluvial and surface water flooding along with impact assessments at local, authority area and national scales. Within the UK, parallel developments in both national scale grid-based flood forecast models and design flood maps and their associated impacts, provides an opportunity to meet this demand for real-time flood risk forecasts.

Across Britain, new joint forecasting centres between the hydrological and meteorological agencies have formed (the Flood Forecasting Centre and Scottish Flood Forecasting Service) and have implemented national scale, grid-based, flood forecasting approaches based on the G2G model [4, 5, 7-9]. The Flood Guidance Statements provided by these joint centres is built on the Flood Risk Matrix approach (Figure 2) that combines potential impact severity and likelihood [2, 3]. In parallel, there has been significant investment in developing next generation pluvial and fluvial flood maps [16, 17, 19, 24] together with improved methodologies in categorising the impact $[21,24]$.

This paper has provided three examples of how realtime $\mathrm{G} 2 \mathrm{G}$ ensemble forecasts of river flow or surface runoff can be combined with pre-calculated "impact libraries" to assess the impact severity of each ensemble member, and, ultimately provide automated methods for estimating the fluvial or pluvial flood risk aligned to the Flood Guidance Statement methodology. The approaches can be applied at pixel or regional level although care must be taken to assess regional impact for each ensemble member before assessing likelihood.
Significant thought and effort has gone into developing succinct displays or products that allow operational users to quickly assess whether further interrogation of the forecast is required and, if so, where to focus attention.

The forecasting of flood impact and risk for example case studies of Surface Water Flooding have been investigated in detail and served to highlight the potential benefits of such approaches. The operational trial by SEPA/SFFS during the Glasgow 2014 Commonwealth Games [10] was deemed beneficial by users and, although only for a limited 10 by $10 \mathrm{~km}$ city area, provided valuable insights into how an operational service might be rolled out to other areas of Scotland. Similarly the Natural Hazards Partnership is developing a real-time end-to-end trial system within the Flood Forecasting Centre. This followed a proof-of-concept stage that included several case studies and a current phase that widens the set of case studies and provides an opportunity to refine the component methods further. The fluvial impact and risk forecasting example for Scotland is at an earlier stage. Nevertheless, the fluvial case study has shown the potential benefit of the simple approach.

In conclusion, the modelling and methodological tools exist to make real-time national scale impact and risk forecasts from pluvial and fluvial sources a reality. Whilst elements of the methodology can always be refined or improved, and more evidence gathered, a move from real-time flood hazard forecasting to real-time flood risk forecasting would represent a significant step forward. 


\section{Acknowledgements}

Financial support for this work from the Centre of Expertise for Waters (CREW) in Scotland, Joint Defra/EA/NRW (Department for Environment, Food and Rural Affairs/Environment Agency/Natural Resources Wales), SEPA and Go Science is gratefully acknowledged. The National Capability Programme of the Centre for Ecology \& Hydrology also supported this work and writing of the paper. Support and data from the Flood Forecasting Centre, Scottish Flood Forecasting Service, Environment Agency, Natural Resources Wales, SEPA and the Met Office is also acknowledged.

\section{References}

1. Cabinet Office (2008). The Pitt Review: Lessons learned from the 2007 floods. http://webarchive.nationalarchives.gov.uk/20100807 034701/http://archive.cabinetoffice.gov.uk/pittreview thepittreview/final_report.html.

2. Flood Forecasting Centre (2013). Flood Guidance Statement - User Guide Version 2.1 May 2013. http://www.ffc-environmentagency.metoffice.gov.uk/services/FGS_User_Guide. pdf

3. Scottish Flood Forecasting Service (2015). Your guide to using the Flood Guidance Statement. Third publication.

http://www.sepa.org.uk/media/149570/sffs_fgs_user guide_2015.pdf

4. Price, D., Hudson, K., Boyce, G., Schellekens, J., Moore, R.J., Clark, P., Harrison, T., Connolly, E. and C. Pilling (2012). Operational use of a grid-based model for flood forecasting. Water Management, 165(2), 65-77.

5. Cranston, M., Maxey, R., Tavendale, A., Buchanan, P., Motion, A., Cole, S., Robson, A., Moore, R.J. and A. Minett (2012). Countrywide flood forecasting in Scotland: challenges for hydrometeorological model uncertainty and prediction. In: Weather Radar and Hydrology (ed. by R. J. Moore, S. J. Cole \& A. J. Illingworth) (Proceedings Exeter Symposium, April 2011), IAHS Publication 351, 538-542.

6. Civil Contingencies Act (2004) Chapter 36. http://www.legislation.gov.uk/ukpga/2004/36/conten $\underline{\text { ts }}$

7. Moore, R. J., Cole, S. J., Bell, V. A. and D. A. Jones (2006). Issues in flood forecasting: ungauged basins, extreme floods and uncertainty. In: I. Tchiguirinskaia, K. N. N. Thein \& P. Hubert (eds.), Frontiers in Flood Research, 8th Kovacs Colloquium, UNESCO, Paris, June/July 2006, IAHS Publication 305, 103-122.

8. Bell, V. A., Kay, A. L., Jones, R. G., Moore, R. J. and N. S. Reynard (2009). Use of soil data in a gridbased hydrological model to estimate spatial variation in changing flood risk across the UK. Journal of Hydrology, 377, 335-350.
9. Cole, S.J. and R. J. Moore (2009). Distributed hydrological modelling using weather radar in gauged and ungauged basins. Advances in Water Resources, 32, 1107-1120.

10. Moore, R. J., Cole, S. J., Dunn, S., Ghimire, S., Golding, B. W., Pierce, C. E., Roberts, N. M. and L. Speight (2015). Surface water flood forecasting for urban communities, CREW report CRW2012_03, CREW, 32pp. www.crew.ac.uk/publications

11. Met Office (2016). The Met Office ensemble system (MOGREPS).

http://www.metoffice.gov.uk/research/areas/dataassimilation-and-ensembles/ensembleforecasting/MOGREPS (last accessed 22 February 2016).

12. Seed A. (2003). A dynamic and spatial scaling approach to advection forecasting. Journal of Applied Meteorology, 42, 381-388.

13. Bowler, N. E. H., Pierce, C. E. and A. W. Seed (2006). STEPS: A probabilistic precipitation forecasting scheme which merges an extrapolation nowcast with downscaled NWP. Quarterly Journal of the Royal Meteorological Society, 132, 2127 2155.

14. Seed, A. W., Pierce, C. E. and K. Norman (2013). Formulation and evaluation of a scale decomposition-based stochastic precipitation nowcast scheme. Water Resources Research, 49, 6624-6641, 2013.

15. Werner, M., Schellekens, J., Gijsbers, P., van Dijk, M., van den Akker, O. and K. Heynert (2013). The Delft-FEWS flow forecasting system. Environmental Modelling \& Software, 40, 65-77.

16. Scottish Government (2013). Surface Water Management Planning Guidance, Flood Risk Management (Scotland) Act 2009. Scottish Government, 56pp. http://www.gov.scot/Resource/0041/00413778.pdf

17. JBA Consulting, Mott MacDonald (2013) Derivation of a Regional Pluvial Flood Hazard Dataset, Scotland - Methodology Report. Draft Report to SEPA, February 2013, 28pp plus Appendices.

18. Cole, S. J., Moore, R .J., Aldridge, T., Lane, A. and S. Laeger (2013). Real-time hazard impact modelling of surface water flooding: some UK developments. Int. Conf. on Flooding Resilience (ICFR 2013), 5-7 September 2013, University of Exeter, UK, 6pp.

19. Environment Agency (2013). Updated Flood Map for Surface Water - National Scale Surface Water Flood Mapping Methodology. Final Report, Version 1.0 (May 2013). Environment Agency, Bristol, UK, 54pp.

20. Faulkner, D. S. (1999). Rainfall frequency estimation. Flood Estimation Handbook, Volume 2. Institute of Hydrology, Wallingford, UK.

21. Aldridge, T., Gunawan, O., Moore, R.J., Cole, S.J. and D. Price (2016). A surface water flooding impact library for flood risk assessment. $3^{\text {rd }}$ European Conference on Flood Risk Management (FLOODrisk2016), 17-21 October 2016, Lyon, France, 10pp. 
22. Health and Safety Laboratory (2008). Updating and improving the National Population Database to National Population Database 2, HSE Research Report: RR678.

23. Environment Agency (-). National Receptors Dataset. $\quad$ https://data.gov.uk/dataset/nationalreceptor-dataset-afa171

24. SEPA (2011). National Flood Risk Assessment Methodology. SEPA report, Scotland, 35pp. http://www.sepa.org.uk/media/99914/nfra_method_v 2.pdf 